\title{
Investigating the Capability of Precision in Robotic Grinding
}

\author{
Mohammed Sufian, Xun Chen, Dingli Yu \\ General Engineering Research Institute \\ Liverpool John Moors University (LJMU) \\ Liverpool, United Kingdom \\ M.Sufian@2016.1jmu.ac.uk, X.Chen@1jmu.ac.uk,D.Yu@ljmu.ac.uk
}

\begin{abstract}
Most robotic grinding focus on the surface finish rather than accuracy and precision. However ever increased demand on complex component manufacture requires to advance robot grinding capability so that more practical and competitive accurate systems can be developed. The current study focuses on improving the level of accuracy of robotic grinding, which is a significant challenge in robot application because the kinematic accuracy of robot movement is much more complex than normal CNC machine tools. Aiming to improve accuracy and efficiency the work considers all quality of measures including surface roughness and the accuracy of size and form. For that to be done, a repeatability test is firstly preformed to observe the distributions of the joint positions and how well the robot responds to its programmed position using a dial gauge method and a circuit trigger method. After that, a datum setting method is performed to assess the datum alignment with the robot. Hence, a mathematical model based on regression analyses applies towards the collected data to observe closely any error correlation when setting up a datum to perform the grinding procedure.
\end{abstract}

Keywords - Robot, Repeatability, Datum identification

\section{INTRODUCTION}

The use of robots in industrial applications has been widespread in the manufacturing industry from handling to production tasks such as welding, sealing, finishing, deburring, flattering, polishing and grinding. Robots have the ability to create cutting cycles in $\mathrm{X}, \mathrm{Y}$ and $\mathrm{Z}$ linear directions as well as two additional rotary axes, often defined as A and B. This rotary axis can tilt the position of the tool or the workpiece in many different ways, which adds flexibility and uncertainty in machining complex parts with complex geometry surfaces. Robotic machining have been found very attractive in many industrial applications as many believe that it decreases machining time and produces a quality surface finish. According to the white paper published by the robotic industries association in 2009 [1], the robotic machining products and services constitute less than $5 \%$ of existing robotic sales, but was seen as a growth application segment in the future. Applications involve the pre-machining of parts made from harder materials, with robots performing various processes at loose tolerances. Due to the limited robot rigidity and payload, the applicable depth of cut and feed rate must be kept small, which limit the material removal rate and the machining efficiency [2]. Therefore, most robotic grinding focuses on the surface finish improvement, but not on the accuracy of component size and form in the process. However, considering the excellent flexibility of robots, a great potential may exist for a robot to carry out surface repair work by facilitating $\mathrm{CAD} / \mathrm{CAM}$, intelligent sensing and control algorithms.

Generally, to achieve high precision robot grinding, it is important to understand interrelationship between process variables and to assure reliable datum identification and process repeatability. Subsequently, mathematical models are required to predict the desired position to create a reliable datum reference point. Many different attempts have been proposed, for example, Kim et.al [3] developed a mathematical model based on multiple regression to evaluate the relationship of variables achieved from different positions on bead plate welds for controlling robot for arc welding.

This paper presents a current research work in Liverpool John Moores University (LJMU) that focuses on improving the level of accuracy in robotic grinding precision, which is a significant challenge in robot applications because the kinematic accuracy of robot movement is much more complex than normal computer numerical control (CNC) machine tools. The initial work includes performing repeatability tests as well as finding a reference datum finding to support the process monitoring and control strategy to provide a reliable and accurate movement, and to ensure smooth grinding and surface finishing.

\section{ROBOT REPEATBILITY}

Industrial robots are used in many applications but still cannot compete with computer numerical control (CNC) machine tools for multiple axis applications in terms of accuracy and repeatability. Repeatability is the ability of a robot to return to the same spot with minor slightest variation whereas accuracy is a measure of the distance error associated with the desired and achieved point. These two factors are interrelated and most commonly used amongst all machining performance characteristics.

Environmental conditions, calibration issues and machine wear may influence the accuracy and repeatability, which may be improved by applying suitable compensation algorithms. Therefore, it is important to determine the repeatability of a robot when considering them for specific applications such as grinding of components. 
The repeatability of industrial robots has been investigated by many researchers in recent years. Brethe et.al [4] investigated the repeatability of a KUKA industrial robot and the distributions of the angular positions of the joints to show that these distributions can be considered as Gaussian. They computed a repeatability test at different locations within the workspace of the robot using the experimental angular covariance matrix and the stochastic ellipsoid modelling. A high variability was observed in the measured data and a method of drawing the distribution of the 15 sample repeatability index is used to compare the computed and measured repeatability. Riemer and Edan [5] evaluated the impact of target location on robot repeatability. Experimental results showed a significant statistical difference between repeatability at different work-volume locations. Especially the height of the target point was found to be a major factor determining the repeatability of a point within the workspace. However, the most common used method of performing repeatability on industrial robots is based on the requirement of ISO 9283:2003 standard [6]. This standard has the scope of conductance of specified tests to develop and verify individual robot specifications, prototype or acceptance testing. The method is used to determine the error in repeatability of robot positioning in order to conduct a series of measurements in the workspace. It is used by robot manufactures and yet it is not highly practical for users due to the limited information obtained in this manner [7]. In order to understand the performance of an articulated industrial KUKA robot in use, a set of experiments is designed to evaluate its repeatability and after that a suitable work procedure is established to identify a best reference datum location on the workpiece for minimum local position error for the robot operation. The fundamental objective of repeatability tests is to observe how well the robot will return to its programmed location at selected minimum positions using a suitable position gauge method.

\section{DATUM LOCATION}

Datum identification is a concept used in engineering to position and tolerate an object in the robot work envelop to create a reference system for measurement. A mathematical modelling method - regression is commonly used for estimating the relationship between one or more dependent variables so that workpiece surface models could be established. One of the challenges in robotic machining is the determination of the datum of workpiece in relation to the robot datum in order to define the start point to perform the machining procedure. The traditional methods used in many robotic applications to determine the workpiece datum is mainly using CMM (Coordinate measuring machine) touch probe. Before measuring a surface, it is important to find a reference to define the location of the workpiece corresponding to the tool. Serval researchers has approached different methodologies to define a datum location, for example, Jin \& Jiyong [8] developed a measurement algorithm using three different coordinate systems to find the closest point to the workpiece. The aim of this is to try to eliminate the influence of all sorts of errors on the geometrical accuracy, which is the key for controlling the robot to conduct grinding process. By establishing the geometrical relationship between reference datum and probe point of measurement with a multiple regression mathematical model, the error level of datum accuracy could be assessed based on the repeatability and defined measuring points.

\section{EXPERIMENTAL PROCEDURE}

As the focus is on finding a datum location to perform precision grinding, the performing repeatability is vital to visualize how well the robot responds to its programmed position in order to define a datum. The experiments are done with two different methods, using (1) a dial gauge that being install at the end of the manipulator and (2) a contact probe as the switch of a simple electrical circuit to determine contact and store the contact points into robot computer. A light bulb is connected in to the electrical circuit to indicate contact. By measuring various locations on workpiece surface, the datum plane will be found based on a mathematical regression method. Throughout the planning phase of the experiments, some control variables were determined to assess the repeatability of the robot. The control variables are presented in Table 1, which lists related information including robot moving speed, payload, work envelope location, motion type. The presence of points to create the desired path are all shown in table 1.

TABLE I.

\begin{tabular}{|l|l|l|l|l|}
\hline $\begin{array}{l}\text { Control } \\
\text { Variable }\end{array}$ & Normal Range & $\begin{array}{l}\text { Measurement } \\
\text { Accuracy }\end{array}$ & Setting & $\begin{array}{l}\text { Predicted } \\
\text { Effects }\end{array}$ \\
\hline Speed & $0-2 \mathrm{~m} / \mathrm{s}$ & $\begin{array}{l}\text { Based on robot } \\
\text { controller }\end{array}$ & $\begin{array}{l}10 \% \text { \& } 30 \% \text { of } \\
\text { normal speed }\end{array}$ & Significant \\
\hline Payload & $0-16 \mathrm{~kg}$ & Scale unit & None & Significant \\
\hline $\begin{array}{l}\text { Workspace } \\
\text { location }\end{array}$ & $0-1610 \mathrm{~mm}$ & variable & $\begin{array}{l}4 \text { points within } \\
\text { workspace }\end{array}$ & $\begin{array}{l}\text { Questionable } \\
\text { significance }\end{array}$ \\
\hline Motion type & Discrete & Variable & $\begin{array}{l}\text { Point to point, } \\
\text { Linear }\end{array}$ & $\begin{array}{l}\text { Questionable } \\
\text { significance }\end{array}$ \\
\hline $\begin{array}{l}\text { Intermediate } \\
\text { points }\end{array}$ & $\begin{array}{l}\text { More than one } \\
\text { point to create } \\
\text { the desired path }\end{array}$ & $\begin{array}{l}\text { Store random } \\
\text { points than span } \\
\text { the entire } \\
\text { workspace }\end{array}$ & $\begin{array}{l}\text { Store couple of } \\
\text { points to target } \\
\text { location }\end{array}$ & Significant \\
\hline
\end{tabular}

Firstly, a dial gauge indicator with $0.005 \sim 5 \mathrm{~mm}$ was used to measure the position repeatability of the robot. The indicator is securely mounted on the robot arm at the end joint to ease the measurement procedure and to ensure accuracy. For each run, the robot controller adjusts the motion and meets the conditions adapted in the robot. A single algorithm was created to run the robot with two different speeds to assess the consistency. A constant robot overall speed is set to $2 \mathrm{~m} / \mathrm{s}$ the measurement is done at $10 \%$ and $30 \%$ of this speed to take at 4 different positions on work table shown in Fig. 1. 

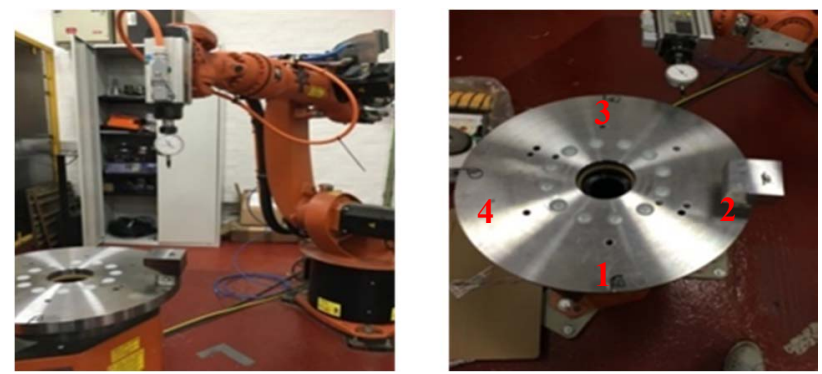

Figure 1. Robot WorkSpace

After that, a circuit contact method is constructed and performed based on the ideal location from repeatability. This method is a procedure where a probe is used as a circuit switch and connected to the robot controller to trigger points respectively so as to determine the contact points at the surfaces of the workpiece block along with 3 Cartesian coordinate directions $(\mathrm{x}, \mathrm{y}, \mathrm{z})$. When the probe contacts the workpiece surface, the bulb in the circuit lights up and the robot controller registers the contact point position in the robot workspace. Fig. 2 illustrates a 3D model of the three surfaces of the block used for detection. The moving path for a robot is under the robot global coordinate system, which works as the base to define the position of the workpiece in relation to the robot. The identified workpiece datum will act as the reference point to perform grinding operation.

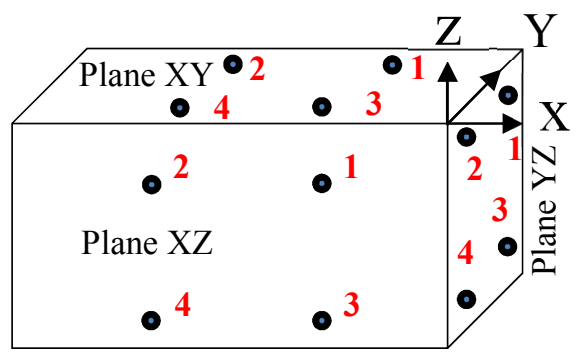

Figure 2. 3D Model of Surface Block with Positions

\section{DATUM PLANE MODELLING}

The multiple regression analysis is most useful to determine the relationship between one dependent variables to multiple independent variable with the best accuracy. It is a statistical technique that allows us to determine the correlation between a continuous dependent variable and two or more continuous or discrete independent variables. It can be used for a variety of purposes such as analyzing of experimental, ordinal, or categorical data. For example, Reddy et.al [9] used multiple regression to predict surface roughness based on all cutting parameters such as feed rates, depth of cut and cutting speed in a turning operation.

However, in this experiment a multiple regression model is performed towards the data collected from robot measurement with minimum estimation errors. Mathematical formula is derived to be calculated by Matlab software first. A matrix calculation formula was then made ready for robot implement. The proposed calculations are made to observe the difference in error correlation between experimental and model calculated results of each point on the $\mathrm{XY}, \mathrm{YZ}$ and $\mathrm{XZ}$ planes.

A common formula of a plane in space can be presented as:

$$
a X+b Y+c Z+d=0
$$

where variables $\mathrm{X}, \mathrm{Y}$ and $\mathrm{Z}$ are the coordinates of the points on the plane; $a, b, c$ and $d$ are constants that defines the plane position. All points coordinates on the plane should satisfy the equation 1 , therefore:

$$
a X_{i}+b Y_{i}+c Z_{i}+d=0 \quad \text { for } i, \ldots, n
$$

Considering the measurement errors $\varepsilon$, the measured points on plane XY should satisfy:

$$
Z_{i}=b_{0}+b_{1} X_{i}+b_{2} Y_{i}+\varepsilon_{i} \quad \text { for } i, \ldots, n
$$

where $b_{0}=-d / c, b_{1}=-a / c$ and $b_{2}=-b / c$. By defining $\mathbf{Z}=$ $\left(Z_{1}, Z_{2}, \ldots, Z_{n}\right)^{\prime}, \mathbf{B}=\left(b_{1}, b_{2}, \ldots, b_{n}\right)^{\prime}, \boldsymbol{\varepsilon}=\left(\varepsilon_{1}, \varepsilon_{2}, \ldots, \varepsilon_{n}\right)^{\prime}$ and

$$
\mathrm{X}=\left(\begin{array}{ccc}
1 & X_{1} & Y_{1} \\
1 & X_{2} & Y_{2} \\
\vdots & \vdots & \vdots \\
1 & X_{n} & Y_{n}
\end{array}\right)
$$

then, the regression function becomes

$$
\mathbf{Z}=\mathbf{B X}+\boldsymbol{\varepsilon}
$$

By solving the equation 4, the coefficients of plane XY can be calculated by

$$
\mathbf{B}=\left(\mathbf{X}^{\prime} \mathbf{X}\right)^{-1} \mathbf{X}^{\prime} \mathbf{Z}
$$

With multiple regression, the equations of workpiece datum planes $\mathrm{XY}, \mathrm{YZ}$ and $\mathrm{XZ}$ can be established with minimum estimation errors. The workpiece datum point is the intersect point of three workpiece datum planes $X Y$, $\mathrm{YZ}$ and $\mathrm{ZX}$ and errors could be identified. By differentiating the workpiece-datum-point function in relation to the measurement repeatability in $\mathrm{X}, \mathrm{Y}$ and $\mathrm{Z}$ directions, the estimation error of workpiece datum point due to the measurement could be estimated.

\section{RESULTS \& DISCUSSIONS}

Firstly, the repeatability test results are shown for all positions at three different coordinate directions $(\mathrm{X}, \mathrm{Y}, \mathrm{Z})$. The test is taken at two different speeds and a $100 \mathrm{~mm}$ offset distance are set for each measuring point to allow the dial gauge to perform the detection process. 


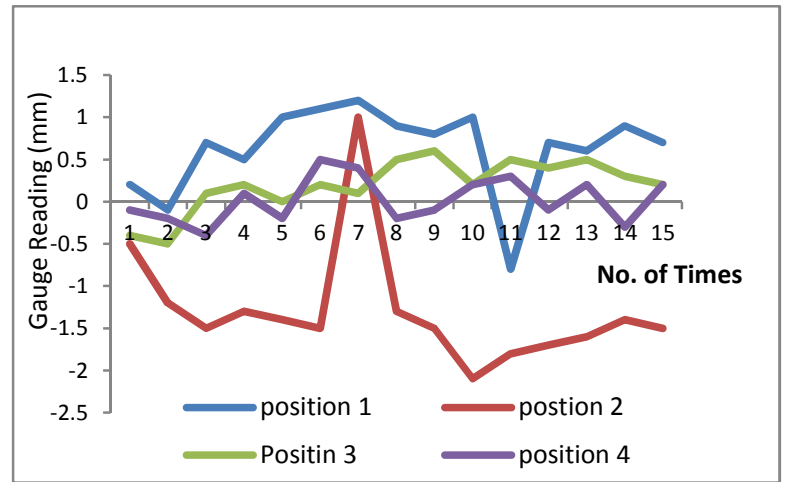

(a) Plane YZ: $100 \mathrm{~mm}$ offset and $30 \%$ of $2 \mathrm{~m} / \mathrm{s}$

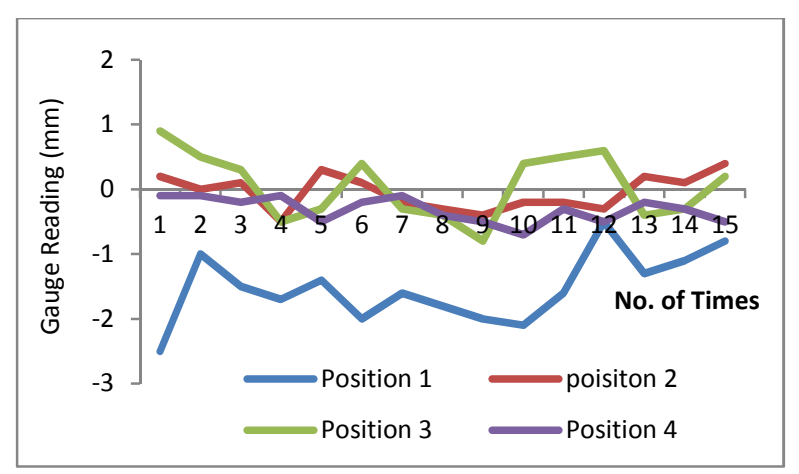

(b) Plane XZ: $100 \mathrm{~mm}$ offset and $30 \%$ of $2 \mathrm{~m} / \mathrm{s}$

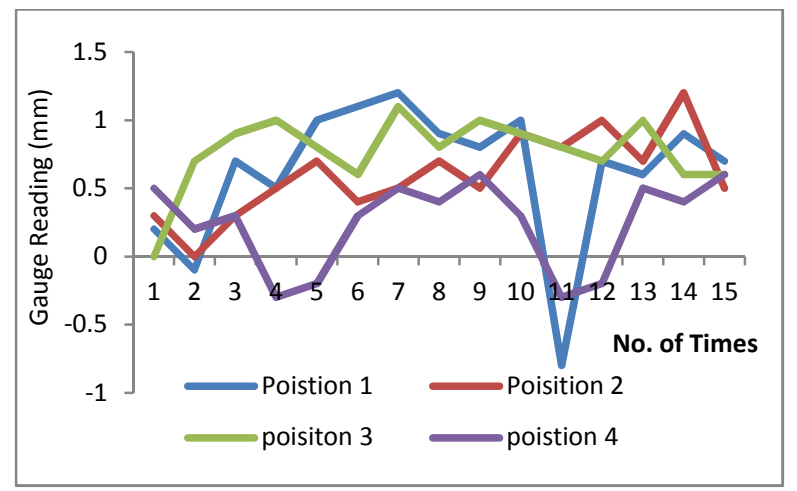

(c) Plane XY: $100 \mathrm{~mm}$ offset and $30 \% 2 \mathrm{~m} / \mathrm{s}$

Figure 3. Dail gauge method - test 1

Fig. 3 shows the results from the experiment test for three plane surfaces and four positions to insure consistency within the experiment. Each point is detected by taking $(\mathrm{x}, \mathrm{y}, \mathrm{z})$ coordinates and each plane surface is considered according to the global movement of the robot. Based on the test under $30 \%$ of $2 \mathrm{~m} / \mathrm{s}$ speed, the repeatability shows high variations in all positions. The maximum variation can reach $3 \mathrm{~mm}$ in $\mathbf{x}$ direction, $2 \mathrm{~mm}$ in $\mathbf{y}$ direction and $2 \mathrm{~mm}$ in $\mathbf{z}$ direction. However, looking at variation of the results under the $10 \%$ of the speed of the robot the errors become smaller. The kinematics of the robot often effects the position and orientation of each joint, this also effected the repeatability which reduces the stability position when detecting each point. However, the maximum variations are all smaller than $1 \mathrm{~mm}$. Therefore, this indicates that the slower the approaching speed the better repeatability can be achieved which is proved by the proposed concept in this experiment.

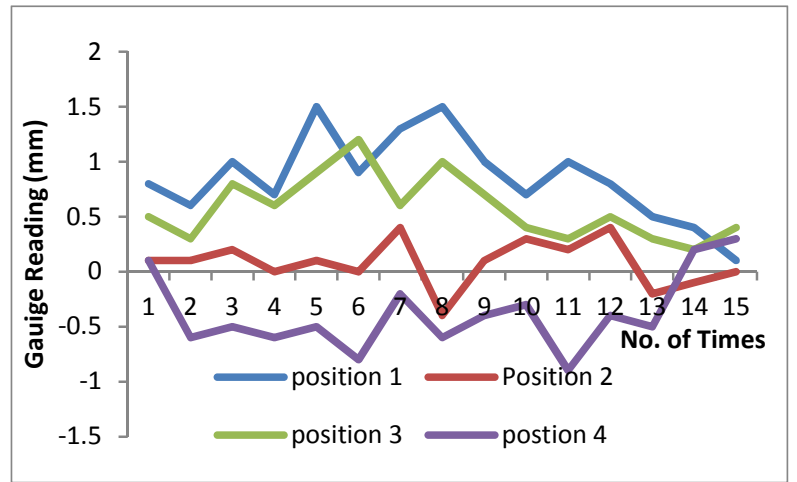

(a) Plane YZ: $100 \mathrm{~mm}$ offset and 10\% $2 \mathrm{~m} / \mathrm{s}$

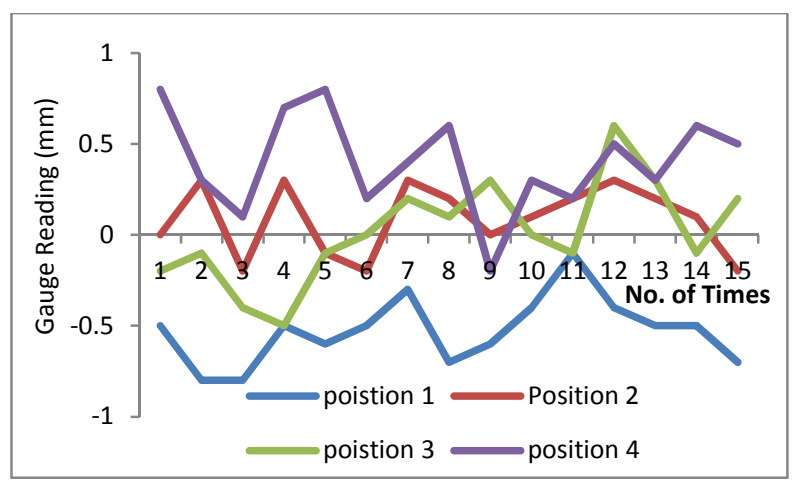

(b) Plane XZ: $100 \mathrm{~mm}$ offset and $10 \%$ of $2 \mathrm{~m} / \mathrm{s}$

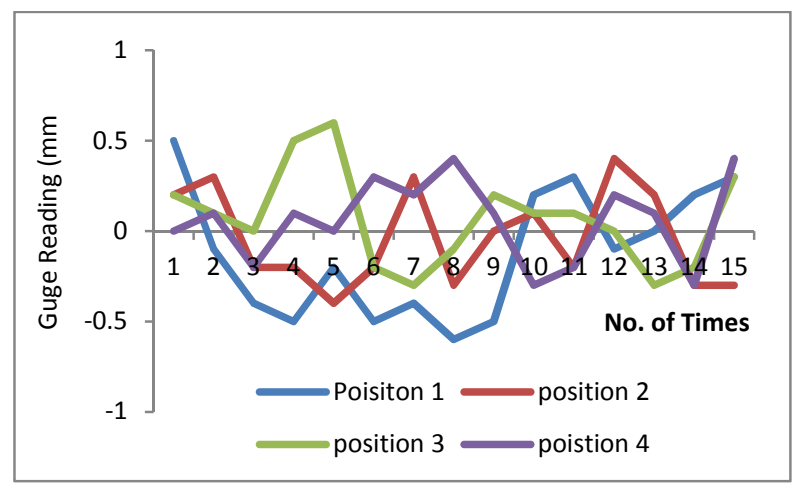

(c) Plane XY: $100 \mathrm{~mm}$ offset and $10 \%$ of $2 \mathrm{~m} / \mathrm{s}$

Figure 4. Dail gauge method - test 2

Considering the situation of $30 \%$ of $2 \mathrm{~m} / \mathrm{s}$ speed, the variations at position 1 for the three Cartesian coordinates is approximately $20 \%$ higher than positon 2 . Position 3 and 4 also share a similar similarity, this variation is due to the position of the robot were the robot stiffness on joints effects to repeatable momentum when measuring the points at different positions, offset distance also play a major role in which it causes deviations of the end effector position on the robot.

The results from position 2, 3 and 4 show a similar variation in terms of expected readings at $100 \mathrm{~mm}$ offset and $10 \%$ of the speed. Depending on the block position on the workspace and the coordinate the robot is detecting, results show there is significant differences in all positions. For example, on plane $\mathrm{X}$ positon 3 and 1 are high over the limit of zero were we expected to be whereas positon 2 and 4 are closer to the zero limit by few millimeters. This indicates that the repeatability at this point is very good 
due to the fact that the variation in reading is close to the zero point which was expected. In another hand, looking at plane $\mathrm{Y}$ and $\mathrm{Z}$ in all positions the variation in results is expected due to the changes of locations of the block in the work table. The main challenge of robots is that their low positioning accuracy and stiffness in the gears and bearings of the joints and the structure. Therefore, the variations in these results could be the main reason for trajectory errors during repeatability process. However, it can be seen from both speeds that the higher the speed percentage the less likely the repeatability result will perform well and gauge reading will not become zero. Therefore, position 2 seems to be the best fit result for the repeatability process as it shows that it is more consistent and readings become close to the initial point (zero).

The second experiment is for the datum identification in order to eliminate the influence of measuring errors on the geometrical accuracy. The experiment is conducted by using an electrical circuit to detect four different points at $\mathrm{XY}, \mathrm{YZ}$ and $\mathrm{XZ}$ datum planes, which are minimum number for using the regression method. The 4 points on each datum plane are illustrated in Fig. 2. Each point detected is based on equal distance from each sides of the plane of the workpiece to allow an approximate full detection of the whole plane. For example, looking at plane $\mathrm{XY}$ the robot travels at only $\mathrm{x}$ or $\mathrm{y}$ coordinate directions to next test point while remains constant at $\mathrm{z}$ direction. In this way, the accuracy and repeatability $\mathrm{z}$ measurement can be assured. Coordinates was collected based on the average value of three trials to ensure consistency in results, total average of data in each plane are given in Table II, in which a similar level of data variations presents for all planes.

Based on detected data a regression mathematical model is conceded to estimate the error correlation. All data points are collected based on global coordinate system movement of the robot. This movement usually consists of a point coordinate $(x, y, z)$ and may include additional information such as velocity, orientation, or angular velocity. In this test, the robot moving speed is $0.2 \mathrm{~m} / \mathrm{s}$. For regression analyses only $(\mathrm{x}, \mathrm{y}, \mathrm{z})$ coordinates are required. The theoretical method is based on equation 3, 4 and 5 shown in the mathematical model section, a set of matrices is used integrate data to for each plane to visualize the error correlation. The matrix solution shown in equation 5 can implement in robot procedure to determine the workpiece datum plane in the robot coordinate system. Table III shows results from theoretical calculations in comparison of measurement results.

TABLE II.

\begin{tabular}{|l|l|l|l|}
\hline \multicolumn{4}{|c|}{ Plane YZ } \\
\hline \multicolumn{4}{|c|}{ Coordinates (mm) } \\
\hline & X & Y & Z \\
\hline Point 1 & 757.5505 & -872.4713 & 691.8712 \\
\hline Point 2 & 761.6895 & -828.6039 & 688.4370 \\
\hline Point 3 & 761.9666 & -828.6090 & 709.7807 \\
\hline Point 4 & 757.4148 & -874.7289 & 709.7308 \\
\hline
\end{tabular}

\begin{tabular}{|l|l|l|l|}
\hline \multicolumn{4}{|c|}{ Plane XZ } \\
\hline & X & Y & Z \\
\hline Point 1 & 819.2446 & -694.7758 & 715.1779 \\
\hline Point 2 & 857.8146 & -692.9856 & 715.0903 \\
\hline Point 3 & 857.8088 & -693.1253 & 699.4367 \\
\hline Point 4 & 816.1471 & -695.2156 & 699.5415 \\
\hline
\end{tabular}

\begin{tabular}{|l|l|l|l|}
\hline \multicolumn{4}{|c|}{ Plane XY } \\
\hline \multicolumn{4}{|c|}{ Coordinates (mm) } \\
\hline & X & Y & Z \\
\hline Point 1 & 856.3293 & -823.6441 & 762.4155 \\
\hline Point 2 & 826.7246 & -823.6226 & 761.6107 \\
\hline Point 3 & 824.9632 & -869.3411 & 761.6254 \\
\hline Point 4 & 852.2498 & -872.1230 & 761.5779 \\
\hline
\end{tabular}

In robot learning stage it is quite often to use statistical methods to observe the movement of the robot. The data taken from the circuit detection method provide useful assessment of robots responses. The multiple regression method estimates the parameters of workpiece datum planes and provides a response model to assess robot performance. From the regression results the predicted dependent variable known as $\mathrm{x}, \mathrm{y}$ and $\mathrm{z}$ from aforementioned equations were identified. The error is estimated by taking the average difference between the experimental values and the calculated theoretical values (see table III) for each plane to eliminate the influence errors on the geometrical accuracy. For example, plane YZ the independent variable $(\mathrm{X})$ from regression is calculated for each point. It can be seen that the average error is around $0.107 \mathrm{~mm}$ but there is one big error of $1.0269 \mathrm{~mm}$ that require further investigation to identify the reason. The results indicate that repeatability at low speed is more desirable in finding accurate datum position for performing robotic grinding.

\section{CONCLUSION}

A repeatability test is presented in this paper to observe the distributions of the joint positions and how well the robot responds to its programmed position using a dial gauge method and a circuit trigger method. After that, a datum setting method is performed to assess the datum alignment with the robot. Hence, a mathematical model based on regression analyses is developed towards the collected data to observe closely any error correlation when setting up a datum to perform the grinding procedure.

Based on the collected data the following conclusions are as follows:

- Better repeatability is achieved based on the low robot moving speed

- Minimum error is achieved based on the $10 \%$ of robot speed, whereas at the higher speed the value is approximately $20 \%$ higher. 
- The difference in error indicates that low speed repeatability is more desirable in finding accurate datum position on all planes which proves that the repeatability is constant and the surface plane is approximately straight in terms of its location.

TABLE III

\begin{tabular}{|c|c|c|c|}
\hline \multicolumn{4}{|c|}{ Plane YZ } \\
\hline \multicolumn{4}{|c|}{$\begin{array}{c}\text { Regression values } \\
\mathrm{X}+0.00970 \mathrm{Y}+0.0096 Z+835.4964=0\end{array}$} \\
\hline & $\begin{array}{c}\text { X- Values } \\
\text { (mm) }\end{array}$ & $\begin{array}{c}\text { X-est. } \\
\text { (mm) }\end{array}$ & $\begin{array}{c}\text { Error } \\
(\mathbf{m m})\end{array}$ \\
\hline Point 1 & 757.5505 & 757.508 & 0.0419 \\
\hline Point 2 & 761.6895 & 761.4867 & 0.2030 \\
\hline Point 3 & 761.9666 & 760.939 & 1.0269 \\
\hline Point 4 & 757.4148 & 757.569 & -0.1548 \\
\hline
\end{tabular}

\begin{tabular}{|c|c|c|c|}
\hline \multicolumn{4}{|c|}{ Plane XZ } \\
\hline \multicolumn{4}{|c|}{ Regression values } \\
$0.0463 \mathrm{X}+\mathrm{Y}+0.0199 Z+-746.8700=0$ \\
\hline & $\begin{array}{c}\text { Y - Values } \\
\text { (mm) }\end{array}$ & $\begin{array}{c}\text { Y -est. } \\
\mathbf{( m m )}\end{array}$ & $\begin{array}{c}\text { Error } \\
(\mathbf{m m})\end{array}$ \\
\hline Point 1 & -694.7758 & -694.7069 & 0.0689 \\
\hline Point 2 & -692.9856 & -692.9228 & 0.0627 \\
\hline Point 3 & -693.1253 & -693.2346 & -0.1093 \\
\hline Point 4 & -695.2156 & -695.1615 & 0.0541 \\
\hline
\end{tabular}

\begin{tabular}{|c|c|c|c|}
\hline \multicolumn{4}{|c|}{ Plane XY } \\
\hline \multicolumn{4}{|c|}{$\begin{array}{c}\text { Regression values } \\
0.0142 \mathrm{X}+0.0081 \mathrm{Y}+\mathrm{Z}+756.7175=0\end{array}$} \\
\hline & $\begin{array}{c}\mathrm{Z}-\text { Values } \\
(\mathbf{m m})\end{array}$ & $\begin{array}{l}\text { Z-est. } \\
\text { (mm) }\end{array}$ & $\begin{array}{l}\text { Error } \\
(\mathrm{mm})\end{array}$ \\
\hline Point 1 & 762.4155 & 762.2058 & 0.2096 \\
\hline Point 2 & 761.6107 & 761.7856 & -0.1749 \\
\hline Point 3 & 761.6254 & 761.3903 & 0.2351 \\
\hline Point 4 & 761.5779 & 761.7552 & -0.1774 \\
\hline
\end{tabular}

Finally, despite the limitations of the experiments, such as the number of data, the results were respectable for being consistent in most positions. Some improvements can be made in the planning stage of measurement. For example, the experiment could incorporate multiple dimension space orientation to measure deviations in three dimensions including two angular positons which could be desirable to obtain more consistent higher resolution measurement.

Further improvements that could potentially improve error elimination could be by improving sensor sensitivity such as the use of lasers [10] to measure points accurately. Also, improving the dynamic performance of the robot and identifying error functions so that the error could be compensated

\section{REFERENCES}

[1] Anon., 2009. Robotics Industries. [Online] Available at: www.robotics.org [Accessed 2303 2015].

[2] Chen, Y. \& Dong, F., 2013. Robot machining: recent development and future research issues. The International Journal of Advanced Manufacturing Technology, 66(9), pp. 1489-1497.

[3] Kim, I., Son, J., Kim, I. \& Kim, J., 2003. A study on relationship between process variables and bead penetration for robotic $\mathrm{Co} 2$ arc welding. Journal of Materials Processing Technology, 136(1), pp. 139145

[4] Brethe, J., Vasselin, E., Lefebvre, D. \& Dakyo, B., 2005. Determination of the Repeatability of a Kuka Robot Using the Stochastic Ellipsoid Approach. Proceedings of the 2005 IEEE International Conference on Robotics and Automation, pp. 43394344.

[5] Riemer, R. \& Edan, Y., 2000. Evaluation of influence of target location on robot repeatability. Robotica, 18(4), pp. 443-449.

[6] Dagalakis, N., 1999. Industrial robotics standards. In: Handbook of Industrial Robotics. 2nd ed. New York: Wiley, pp. 59-449.

[7] Brink, J., Hinds, B. \& Haney, A., 2004. Robotics repeatability and accuracy: another approach. Texas Journal of Science, Robotica, 27(3), pp. 149-156.

[8] Jin, T. \& Jiyong, K., 2007. A 3-D point sets registration method in reverse engineering. Computers \& Industrial Engineering, 53(2), pp. 270-276.

[9] Reddy, B., Padmanabhan, G. \& Reddy, K., 2008. Surface roughness prediction techniques for $\mathrm{CNC}$ turning. Asian Journal of Scientific Research , 3(1), pp. 256-264.

[10] Taek, Y., 2015. Study of Datum Location Error on the Accuracy of Industrail Robot. International Journal of Engineering and Technology, 7(3), pp. 833-843

[11]Allen, M. P., 1997. Understanding Regression Analysis. New York \& London: Plenum Press, New York. 